\title{
Reseña
}

\section{Dinámicas locales del cambio ambiental global. Aplicaciones de percepción remota y análisis espacial en la evaluación del territorio}

(Erick Sánchez Flores y Rolando E. Díaz Caravantes, coordinadores. México: Universidad Autónoma de Ciudad Juárez, 2012. 547 páginas)

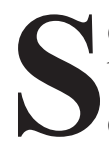
egún los coordinadores de esta publicación, su objetivo es la integración de investigaciones científicas "que ejemplifiquen la aplicación de métodos, técnicas y herramientas de percepción remota y análisis espacial con sistemas de información geográfica en la caracterización de las dinámicas territoriales vinculadas con procesos locales y regionales que inciden en el cambio ambiental global" (p.10). Así, desde la perspectiva territorial se definen las diferentes secciones que conforman la obra: la primera trata sobre la dinámica de uso y cobertura del suelo; la segunda incluye estudios sobre la dinámica del medio ambiente urbano y su alta repercusión en los procesos de cambio ambiental global; la tercera se enfoca en la percepción remota de la vegetación; la cuarta parte se refiere a los modelos de análisis de los recursos hídricos; y la quinta y última sección recoge diversas herramientas geotecnológicas para el análisis del territorio y sus componentes.

Advierten los compiladores sobre la experiencia de los autores que aportaron como expertos de diversas instituciones de México, Brasil y Estados Unidos de América, lo cual enriquece el producto final. 
